\title{
En el contexto uruguayo, narrativas biográficas y lugares sociales de los y las jóvenes
}

Mabela Ruiz Barbot *

Instituto de Psicología, Educación y Desarrollo Humano, Facultad de Psicología de la Universidad de la República

mruiz@psico.edu.uy; mabela.ruiz@gmail.com

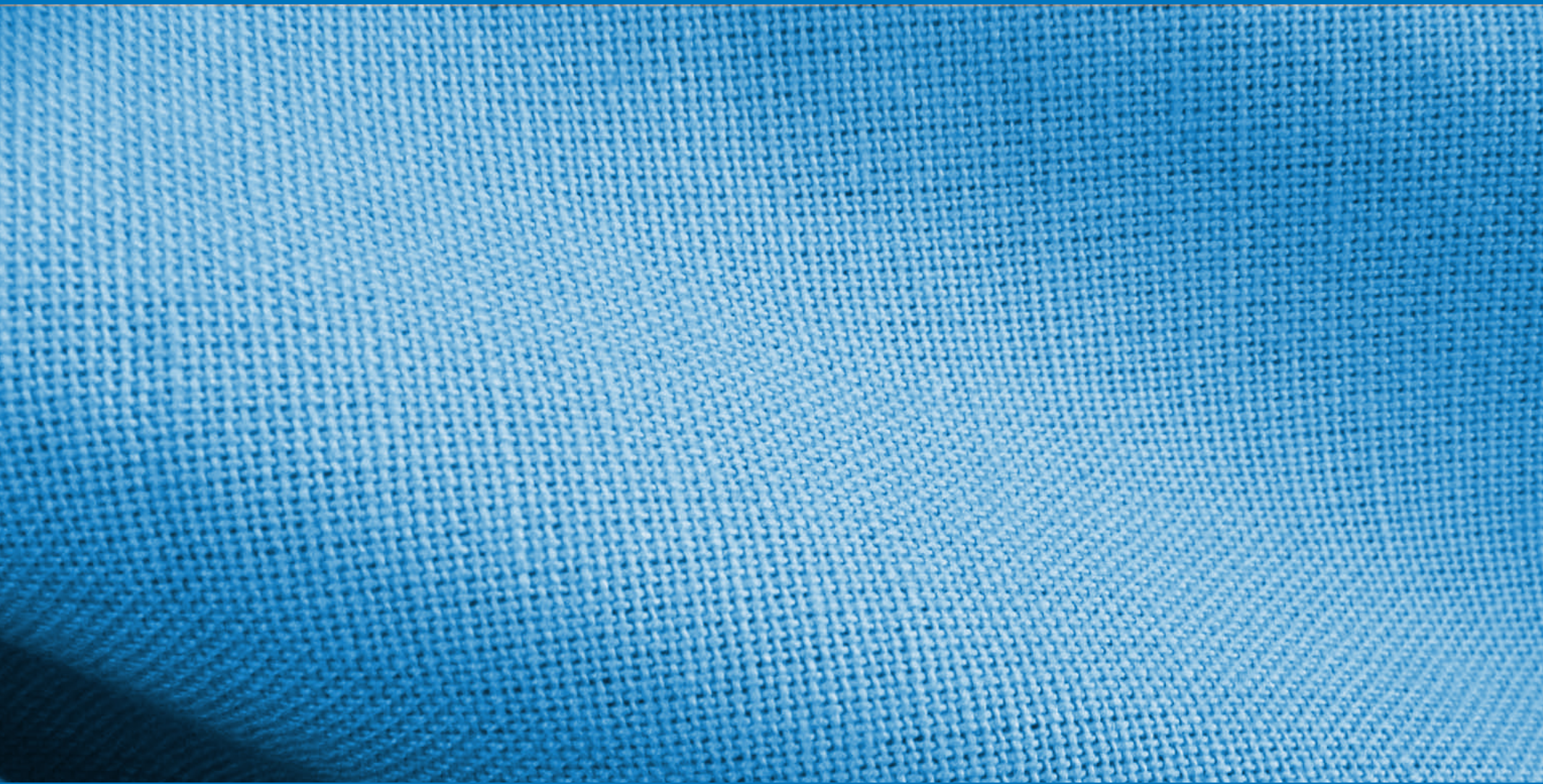




\section{Resumen}

Este artículo presenta las conclusiones de mi tesis de doctorado Narrativas biográficas: condiciones de existencia y lugares sociales de los y las jóvenes, en el contexto uruguayo, llevada adelante en FLACSO-Argentina. En ella, me pregunto por los significados construidos por las personas de entre 18 y 24 años respecto a "lo juvenil" en relación al conjunto social: ¿cómo narran su lugar social jóvenes montevideanos de ambos sexos y de distintos sectores sociales?

El lugar social del que hablo se despliega en el territorio del sentido. No se abarca desde un punto de vista geográfico ni económico o de estratificación social. Es el espacio de las experiencias vitales desde las cuales los/as jóvenes construyen el sentido del sí mismo como joven y de la vida adulta.

El supuesto que guió la investigación es que la polarización social, como condición actual de producción de las experiencias vitales, ha transformado la construcción de las biografías jóvenes. Fundamentalmente, profundiza las desigualdades sociales y configura nuevas identidades de género.

El foco en las narrativas, deudor del giro biográfico en las ciencias sociales e inscripto en la tradición constructivista, permitió revisar cómo los agentes sociales construyen y ponen en sentido sus experiencias vitales.

Palabras claves: Jóvenes - Narrativas-biográficas - Lugares sociales

\section{Abstract}

This article presents the results of the $\mathrm{PhD}$ thesis: Biography narratives: existence conditions and social places of the young people in Uruguayan context, done within the frame of FLACSOArgentina. The thesis asks for the meaning 18 to 24 year-old people construct on the youthful: ¿how young montevidean people of both sexes and from different social sectors narrate their social place?

The social place in question opens out within sense territory. Thus, it does not addressed a geographical, economic or social stratification point of view. It referes to how youths understand themselves as young people and how they build their conceptions of adult life through their experiences.

The assumption guiding this research is that social polarization as present condition of production of vital experiences, has transformed the construction of youth biographies, especially in social inequities and configuring new gender identities.

The focus on narratives, which is a debtor to the biographical point of view in social sciences and is included in the constructivist tradition, allows reviewing how social agents build and put in sense their vital experiences.

Keywords: Youths - Biographical narratives - Social places

Mabela Ruiz Barbot, "En el contexto uruguayo, narrativas biográficas y lugares sociales de los y las jóvenes". Cuadernos del Ciesal. Año 13, número 15, enero-diciembre 2016, pp. 294-313. 


\section{Introducción}

Este artículo presenta las conclusiones de mi tesis de doctorado, titulada: Narrativas biográficas: condiciones existenciales y lugares sociales de los y las jóvenes, en el contexto uruguayo, llevada adelante en el marco del Programa de Doctorado en Ciencias Sociales de FLACSO-Argentina. Conclusiones que conjugan potencialidades teórico-metodológicas inscriptas en las narrativas biográficas que reescribo al cierre de este texto.

En dicha tesis consideramos que valía la pena preguntarse por los significados construidos por las personas de entre 18 y 24 años respecto a "lo juvenil" en relación al conjunto social: ¿cómo narran su lugar social jóvenes montevideanos de ambos sexos y de distintos sectores sociales? Ya que en las condiciones actuales de polarización social tanto las dimensiones inter-generacionales y las formas de construcción de categorías sociales, y trayectorias biográficas se encuentran transformadas. Las instituciones, de mediados y finales del siglo XX, productoras y reproductoras de integración social: el Estado y las organizaciones públicas, la familia y la nupcialidad, la escuela y el trabajo, ya no marcan simbólicamente el lugar social de los y las jóvenes en la transición a la vida adulta ni configuran aquella construcción subjetiva que se denominaba "juvenil" y que articulaba posiciones sociales, narrativas biográficas y trayectorias de los sujetos a los que interpelaba, aparentemente, sin demasiadas contradicciones.

La pregunta central de la tesis adquirió, entonces, las siguientes dimensiones analíticas:

- ¿ ¿ ¿cómo y con qué atributos, se construye la categoría joven para personas de distintos sectores sociales y de ambos sexos?

- ¿qué valor/es adquiere la "juventud" en la narración de las experiencias y trayectos biográficos de estas personas?

- ¿Cómo se conectan, diferencian, entran en vinculación o tensión, los lugares sociales asignados a la juventud respecto de la adultez y respecto de la infancia?

El lugar social lo entendimos, a nivel simbólico, como una configuración que entrama al sí mismo y al nosotros, componiendo distintas dimensiones: experiencias vividas (familiares, educativas, laborales, barriales, con amigos/as), relaciones sociales (clase, inter e intra-generacionales, de género, territoriales), espacios institucionales por los cuales transitan los y las jóvenes, códigos lingüísticos que manejan, sentidos que le dan a sus experiencias, formas en que anticipan su por-venir.

Es decir, el lugar social del que hablamos se despliega en el territorio del sentido e interpela la noción de transición a la vida adulta. No abarcamos el lugar social desde un punto de vista físico o geográfico, ni desde un punto de vista económico o de estratificación social. Hablamos del espacio de las

\footnotetext{
* Doctora en Ciencias Sociales FLACSO-Argentina; Magister en Ciencias de la Educación con mención en investigación educativa Centro de Investigación y Experimentación Pedagógica, Uruguay/International Development Research Center, Canadá; Licenciada en Sociología en la Universidad de la República Oriental del Uruguay. Profesora Titular, docente e investigadora en el Instituto de Psicología, Educación y Desarrollo Humano de la Facultad de Psicología de la Universidad de la República. Correos electrónicos: mruiz@psico.edu.uy; mabela.ruiz@gmail.com.
} 
experiencias vitales desde las cuales los y las jóvenes construyen el sentido o la ausencia de sentido del sí mismo como joven y de cómo se ven en la vida adulta — si es que la entienden como vida joven y vida adulta - Hablamos de las experiencias vividas e incorporadas, vividas y narradas, vividas e interpretadas, vividas e imaginadas. Aquello que les pasó y les pasa a los y las jóvenes en el campo socio-histórico y existencial —-material y simbólico- ${ }^{2}$. Lugar social que comparten con otros, desde las condiciones de existencia, el tiempo vivido con esos otros y en la construcción de lazos sociales (Barrios y otros, $2009^{3}$; Gatti, $2008^{4}$; Larrosa, $2003^{5}$ ).

Nos propusimos como objetivo, analizar los tipos de narrativas sobre el lugar social juvenil por parte de jóvenes uruguayos de ambos sexos y de diversos sectores sociales, comprendiendo los límites y variaciones que la polarización social produce en sus biografías.

Un diseño cualitativo, situado en un enfoque biográfico-narrativo a partir de entrevistas individuales en profundidad y entrevistas grupales sustentadas en técnicas expresivas y evocativas, desarrolladas en diferentes encuentros con jóvenes de distintos sectores sociales, fue precisando y enriqueciendo la tesis, en tanto implicó la revisión y reconstrucción del objeto de estudio de modo reflexivo. El foco en las narrativas nos posibilitó revisar cómo los y las jóvenes ponen en sentido sus experiencias vitales, y qué valor le atribuyen a la "juventud". Es decir, recuperar sus voces y leer los sentidos con que construyen sus lugares sociales. Nos posibilitó abordar las relaciones intergeneracionales y societales (conexiones entre adultez-juventud-niñez), observar el carácter político de lo "juvenil" en tanto se traza en respuesta o significación de lo adulto y la niñez. Nos posibilitó historizar su construcción. Comprender los atributos con que construyen la categoría joven desde nuestros dos ángulos de entrada: sexo y clase social. Escuchar sus historias en el análisis de la historicidad, sin dar por sentado que la categoría joven los abarca integralmente como personas. Distintas y desiguales experiencias sociales, institucionales, territoriales, de género, atraviesan sus biografías.

De este modo, el análisis de las narrativas se sustentó en un análisis del discurso desde una perspectiva que situó los textos narrativos en sus contextos de producción. Dejamos que los textos hablasen, sugirieran, produjeran (convocando la voz "joven") y al mismo tiempo, se le hicieron preguntas a los textos. Así se trabajó en un análisis combinado: inductivo y deductivo, desde temáticas emergentes

2. En este artículo incluyo, única y mínimamente, una delimitación conceptual de los lugares sociales y no un raconto crítico de las teorías de juventud -estudios culturales y sobre identidades juveniles-, ni los referentes teóricos relativos a las narrativas y la construcción de biografías, a la experiencia y constitución de los y las jóvenes mediante la misma, a las condiciones de polarización social, a la diferencia sexual así como a la comprensión de los y las jóvenes como categoría social que he elaborado en la tesis, sino que busco en lo posible irlos trabajando desde los datos, siendo consciente de su inabarcabilidad en un artículo y en el privilegio de presentación de estos últimos.

3. Barrios, F. y otros. Decires diversos. Diferencia y construcción de sí. IMM-Montevideo: VI Congreso Uruguayo de Ginecología de la Infancia y Adolescencia, 2009.

4. Gatti, G. El detenido desaparecido. Narrativas posibles para una catástrofe de la identidad. Montevideo: Trilce Ediciones, 2008.

5. Larrosa, J. “Algunas notas sobre la experiencia y sus lenguajes". Serie Encuentros y Seminarios, Departamento. de Teoría e Historia de la Educación, Universidad de Barcelona, en: http://www.ses.me.gov.ar/curriform/oei 20031128/ponencia larosa.pdf, 2003. 
de los relatos de los y las jóvenes y desde preguntas formuladas a estos textos por mí, como investigadora.

Las narrativas biográficas permitieron construir los lugares sociales, que ahora presentamos, como horizontes de sentidos de los y las jóvenes, tendencias significativas a modo de tipos narrativos. Tipos narrativos que no dan cuenta de persona ni joven alguno, son elaboraciones que posibilitaron crear contextos de sentidos a través de la selección y ampliación de algunas dimensiones de las experiencias de vida narradas. No existen más que como construcciones analíticas. Tampoco cada tipo narrativo refiere, necesariamente, a una clase social, más allá que en la construcción de estos horizontes de sentidos predomine una clase sobre otra, dando cuenta de hegemonías, resistencias, alteraciones. Son espacios simbólicos que, como campos de fuerza, se interceptan, cruzan, confrontan y se producen unos a otros, recursivamente.

Emergieron y construimos tres tipos narrativos: un lugar político-naturalizado, un lugar político-paródico y un lugar político-alterado. Lugares sociales que irrumpieron de lo vivido por los y las jóvenes componiendo sentidos, de experiencias que siempre son políticas, de relaciones de control y resistencia. Cada lugar social surge y se construye, narrativamente, en relación a alteridades, a antagonismos, a un otro que niega la propia experiencia y cuestiona la existencia propia o a un otro que interpela y altera al sí mismo (Mouffe, 1996\%; Elizalde, 20087).

\section{Narrativas de un lugar político-naturalizado}

Las experiencias vitales, narradas e interpretadas por unos y unas jóvenes construyen sentidos plurales. Construyen una multiplicación de lugares sociales que, al mismo tiempo, se funden en un sentido de la libertad que implica la posibilidad de elección, de vivir cada uno/a a su libre albedrío, en el intento de realizarse personalmente, en la búsqueda de una identidad propia. Así sienten que eligen una manera de vivir no sólo a futuro sino en el hoy, un modo presente de vida; una manera de vivir que para alguno de ellos cambiará en el tiempo y otros, la proyectan como una manera de vida ilusoriamente estable. Piensan que eligen una identidad activada por el sí mismo, buscando la esencia de cada uno/a, la autenticidad de cada quien. Sienten que develan las simulaciones de otros/as y a su vez, ellos violentan o ridiculizan la vida de los otros. Sienten que reconstruyen y heredan la vida heroica de sus antepasados. Buscan ser los mejores, se sitúan en el descubrimiento y desarrollo de sus capacidades personales, la perfectibilidad, lo exclusivo y excluyente, aspirando al gobierno y regulación de los otros. Eligen pertenencias y referencias grupales del propio entorno - que no se nombra como clase social-, y globales antes que juveniles. Pertenencias que ideológicamente se configuran desde elecciones individuales. Se inscriben en la elección de su "destino" desligado de estructuras sociales que lo producen, estructuras que se niegan. Unos eligen identidades que integran el hedonismo y la excentricidad como diferencia social. Otros seleccionan una vida solitaria. Evitan o niegan

6. Mouffe, Ch. "Por una política de identidad nómada”. Jstor, Vol 14, pp 3-13. http://www.jstor.org/stable/42624359 1996.

7. Elizalde, S. "Debates sobre la experiencia. Un recorrido por la teoría y la praxis feminista”. Revista Oficios Terrestres № 23 , Año XIV. La Plata: Facultad de Periodismo y Comunicación Social, Universidad Nacional de La Plata, 2008. 
el conflicto social, se identifican con las maneras de vivir del "mundo desarrollado". Diluyen la adultez rejuveneciendo al adulto y a sí mismos en el futuro. Piensan que se educan y eligen sus caminos y espacios educativos, informándose y evaluando las ofertas y ventajas institucionales, así como los espacios laborales, negociando posiciones a través de sus deseos, gustos, oportunidades y vínculos. Sienten que tienen iniciativa y toman decisiones, viven en la máquina productivista — "creativa" — y en la aceleración de la vida, en la estimulación continua o en el placer de hacer lo que les gusta. Al mismo tiempo, optan por momentos distendidos, des-estresantes, des-agobiantes, des-contracturantes. Eligen actividades deportivas o artísticas. Hacen golf, juegan al tenis, al rugby. Estilizan el cuerpo re-afirmando la masculinidad hegemónica -ir al gimnasio, "estar medio cuadrado", toman creatina que genera músculos - y resaltan la belleza o estética como símbolo de "la" feminidad aunque re-actualizada - cuerpos producidos, modelados y modelantes-, cuerpos para otros. Silencian la propia masculinidad y dejan fluir la feminidad. Viajan, recorren el mundo, se relacionan internacionalmente y lo ostentan. Así buscarán interrogar a su sí mismo permanentemente o anclarse en identidades sólidas, en una posición esencialista elegida, buscando su "destino" individual en el pasado.

Este sentido de la libertad $-y$ no aquel que hablara Fromm $(1991)^{8}$ relativo a la fuerza y dignidad del ser- como lugar simbólico de jóvenes de sectores medios altos también despliega su fuerza hegemónica atravesando a sectores medios y de los márgenes. Un sentido de la libertad que se bifurca o presenta caras disímiles, según la experiencia de vida singular de cada joven. Narrarán, interpretarán e imaginarán sentidos armónicos de vida, sentidos hedonistas, festivos y "positivos", sentidos estables, sentidos solitarios y de racionalización de la vida, sentidos acelerados, sentidos elitistas y petulantes, de desprecio y maltrato a otros, así como sentidos ilustres y políticos, de dominio.

Dar cuenta de un sentido social, para ellos, será construir el sentido propio de la vida, desde esta mirada, experiencia y práctica social y etaria. Implicará construir espacios de amistad, lugares de aislamiento, prácticas de vida con amigos/as —irse a vivir juntos_, o en pareja — no necesariamente legalizada. Implicará el desarrollo personal, la creación de nuevos lugares laborales o la gestión del propio espacio y tiempo laboral, la formulación continua de proyectos. Involucrará la estilización del cuerpo, el goce de la vida yendo a festivales, recorriendo mundo, consumiendo gustos y felicidad, administrando las propias posibilidades.

Sentidos que ya no tienen que ver con la transición a la adultez, con titularse, acceder al primer empleo o tener un hijo/a, sino con la pseudo-realización personal y la diversificación de la vida. En donde todas las dimensiones de la vida, algunos de estos jóvenes, las ponen en interrogación y experimentación, en tanto que otros las entenderán como una herencia social a individualizar. Será el sujeto quien la elige, componiendo una trama personal selecta de la novela familiar.

Son sentidos que se afirman entre la individualización y normalización de la vida. Así construyen un sentido naturalizado de la existencia social. Heredan, incorporan y narran como natural y normal aquello que es construido histórica y socialmente. Despliegan discursos hegemónicos y fundan hegemonía. Al mismo tiempo que hablan de una multiplicidad de maneras de ser y estar joven, despliegan una voluntad de dominio del otro, planteando estos sentidos propios a lo juvenil como sentidos

8. Fromm, E. El miedo a la libertad. Buenos Aires: Paidós, 1991. 
naturales y legítimos, aunque no lineales. Ponen en juego un discurso que separa, establece fronteras entre los propios jóvenes. Ellos y ellas serían los “jóvenes naturales", los que eligen su destino, personas libres, vitales, potentes, espontáneas, curiosas, con ganas de aprender y avidez de cosas nuevas, de experimentar y descubrir, de disfrutar y gozar la vida, de buscar y elegir identidades pasajeras o estables. Pero cuando califican o caracterizan lo juvenil, también sitúan al joven problemático y este joven siempre es el otro. No es el "yo" joven que narra. Se apropian del discurso social hegemónico y adulto y lo re-significan creando una relación joven-joven desigual, proyectando en los otros/as jóvenes su fragilidad humana no revisada ni reflexionada.

Sus voces, figurativamente, van estableciendo las fronteras y distinciones entre unos y otros. Como jóvenes naturales construyen categorías prácticas ${ }^{9}$ o desigualdades sociales-categoriales ${ }^{10}$ intra-etarias. Categorías que señalan distribuciones desparejas de atributos entre unos y otros, categorías que definen las formas de relacionarse entre personas jóvenes y establecen una brecha intra-generacional.

Las figuras jóvenes que construyen se sostienen en enunciados dicotómicos, en donde el "yo" que narra señala al otro joven en su carencia, falla, error, caos, desmesura, dejadez, fragilidad, violencia, estigma barrial o pueblerino, estigma musical o de la nocturnidad que participa, estigma sexual, consumo de sustancias adictivas. Por lo general, no visualizan las condiciones de vida del otro ni las desventajas o diferencias en que ese otro/a vive. Lo des-conocen y des-reconocen. Y ellos/as mismos se piensan desligados de sus propias condiciones de existencia, sin estructuras que los limiten. O señalan al propio individuo-joven como determinante de sus posibilidades y maneras de vivir, en donde los contextos casi no juegan o son "slogans políticos".

Entonces, desde este sentido naturalizado y el sentido de libertad electiva, el otro también construye su destino sin condicionamiento alguno.

Las figuras jóvenes que construyen y despliegan en enunciados dicotómicos, se traducen en frases tales como: hay jóvenes que quieren superarse todo el tiempo y otros que no piensan en el futuro; están los que quieren aprender y los que no quieren aprender; los que se esfuerzan y los que no quieren nada; los que trabajan y los que no trabajan; los "burgueses y los que viven en barrios"; los que habitan al Sur de Montevideo y los que habitan lejos del Sur -los márgenes, el Noroeste o Noreste-; los que circulan en ómnibus o auto, los que andan en carrito; aquellos que vinieron a Montevideo y estudian en la universidad, y aquellos que se quedaron en el pueblo, en la vida y la adolescencia; los que bailan en Pocitos y los que bailan en la Ciudad Vieja, entre otros; los de la murga joven y aquellos a los que se les lleva un espectáculo con cabeza distinta a la propia; los que escuchan cumbia o plena, los que escuchan rock; los que visten raro, los que visten como uno; los que tienen plata y"se dan la papusa", los que no tienen plata, se drogan y arman lío; los no diversos y los diversos sexualmente.

Establecen verdades y prohibiciones para unos y otros - maneras de vestir que distinguen y diferencian, espacios donde participar y donde no participar, maneras de estar entre ellos y ante los otros,

9. Brubaker R. y Cooper, F. "Más allá de la identidad". Revista Apuntes de Investigación del CECyP, № 7, 2001.

10. Tilly, Ch. La desigualdad persistente. Buenos Aires: Manantial, 2000. 


\section{Mabela Ruiz Barbot}

maneras de tratar a unos y otros, maneras de consumir de unos y otros, maneras de pensar válidas y formas de pensamiento que no conocen, pero invalidan, sexualidades legitimadas y no legitimadas. Refuerzan la noción hegemónica de joven o la categoría joven anticipada desde los adultos, asociada a un joven problema, peligroso, delincuente, anormal, anómico.

Este sentido naturalizado de la vida social construye formas de exclusión juveniles. Instala discursos con voluntad de verdad, en el sentido que le da Foucault (1992) ${ }^{11}$. La calificación y consiguiente descalificación del otro, el des-reconocimiento de las diferencias y desigualdades sociales, la negación de la contingencia y finitud humana, de la mutua humanidad. Instala un lugar social sin conversación de alteridad, un lugar de negación o de afirmación naturalizada de las desigualdades sociales.

\section{Narrativas de un lugar político-paródico}

Las experiencias vitales, narradas e interpretadas por otros y otras jóvenes construyen variaciones de sentidos y al mismo tiempo, un sentido común y epocal de resistencia social. Sentido de resistencia que liga sentidos de agenciamiento de la vida, sentidos vinculares locales, sentidos de cuidado de sí y de un nosotros joven estigmatizado, sentidos de quiebre y re-construcción de sí vertiginosos, sentidos de des-territorialización y re-territorialización de la vida, sentidos de inestabilidad, de desamparo, de la finitud y de lo provisorio de los sentidos en la vida. Sus biografías dan cuenta de una experiencia de dominio provisional de la contingencia (Mêlich, 2006 ${ }^{12}$ ), más allá que representen su vida, unas veces, como "destino" personal. Saben que los sentidos nunca se establecen definitivamente. Van y vienen entre sentidos cambiantes que expresan momentos de sus vidas, un contexto institucional que han habitado o habitan, un barrio en que han vivido o viven y que puede ser otro, una relación de pareja, el cambio de pareja.

Saben moverse en la incerteza, desarrollan el sentido de sobrevivencia, tienen aguante. Saben de pérdidas, dolores, vicisitudes, quiebres, ausencias, maltratos; de goces, alegrías, risas, fiestas, amores. Conocen el sin sentido y lo provocan. Han atravesado momentos y acontecimientos disociados del sentido (delegación de la maternidad, desamparo, prisión de un familiar, fracaso escolar), ante los cuales no han contado con esquemas de pensamiento desde dónde aprehenderlos e interpretarlos o lo han contado entre lenguas, a dos lenguas. Repitiendo el discurso hegemónico y buscando otras palabras que nombren aquello que les pasó. Han conocido el vacío de sentidos y saben re-significar la vida. Cuentan con la posibilidad de deslegitimar el statu quo, de impulsar nuevas búsquedas, construcciones sociales alternativas. Conocen la vigilancia y fugan de la mirada del poder y de la ciencia. Conocen la norma social y la fragilidad humana, la injusticia y el desprecio social, violencias humillantes. Conocen la discriminación, la viven en el día a día. Saben en el lugar estigmatizado en que son situados por otros jóvenes y el conjunto social. Viven la relación desigual entre jóvenes, aunque

11. Foucault, M. El orden del discurso. Buenos Aires: Tusquets Ediciones, 1992.

12. Mèlich, J.C. Transformaciones. Tres ensayos de filosofía de la educación. Miño y Dávila. Buenos Aires, Argentina: Miño y Dávila, 2006. 
no desde la subordinación sino que desde un acatamiento paródico ${ }^{13}$ y politizado. Acatamiento que implica situarse sutilmente en el cuestionamiento a la autoridad de la norma, en un acatamiento distanciado que no es burla sino que muestra a las identidades como ficciones, que subraya, recalca, acentúa el sentido de libertad electiva como construcción discursiva -enunciados que realizan lo que nombran-, y por tanto, como construcción social. Acatamiento que devela la naturalización de esta construcción y la sitúa en su historicidad.

Ellos saben que en el imaginario social ocupan el lugar de los que no quieren aprender, de los que no estudian, los que no trabajan, los que no se esfuerzan, los que no se proyectan a futuro, de quienes tienen hijos/as en la adolescencia. El lugar de los que usan piercing, gorros planchas, de los que escuchan cumbia, de los que toman y trafican merca, de los violentos, los que roban, los que habitan las esquinas, la cárcel, los márgenes, los basurales, los restos sociales.

Pero lo excluido vuelve, se hace presente y se presenta ante lo incluido, provocándolo, desafiándolo, aguijoneándolo, perturbándolo. Quiebra, rompe la normalidad. Señala las ausencias, lo que la inclusión dejó fuera. Estos jóvenes se instalan en espacios callejeros, en la esquina, en los cruces de avenidas con sus malabares, irrumpen en los barrios residenciales. Irrumpen en las redes sociales con imágenes de los márgenes, de la pobreza, del plancha, de la "basura" social, de los lugares "invivibles". Irrumpen con un lenguaje sexuado. Muestran otros lenguajes y la posibilidad de construir nuevos lenguajes. Muestran los sentidos de la incertidumbre, del equilibrio inestable en que viven. Muestran las heridas sociales en sus cuerpos y muestran sus cuerpos. Muestran que están, que existen. Muestran que en las zonas invivibles se hace experiencia, se construyen identidades, se vive. Y esas experiencias se construyen en la exclusión, en un lugar devastado aunque no devastador de la experiencia de sí y de los otros/as. Muestran que allí se construyen sentidos, lugares de existencia posibles. Otra existencia. Una existencia extraña e irreconocible, irrepresentable para los "jóvenes naturales".

Paródicamente, muestran que el joven natural es una construcción histórica, simbólica, cultural, política, social. Y que ellos son la realización de lo que los jóvenes naturales y los adultos nombran, son lo que dejaron afuera, en el exterior. El poder produce los cuerpos que gobierna, dice Butler (2002) ${ }^{14}$, en la reiteración forzada de prácticas y normas. Ellos son los excluidos de la construcción histórica actual. Son el lado oscuro, abyecto, el resto. Ellos no son los mejores, ellos han fracasado en la escuela. Ellos han quedado fuera del mercado laboral formal, ellos no presentan calificaciones laborales. Ellos no son perfectos, no son eficientes. Ellos son "quedados", no quieren superarse. Ellos escuchan cumbia. Y lo muestran, lo multiplican, lo amplían. Encarnan la fragilidad - lo que otros/as, ilusoriamente, despojan de sí- y también la potencia. Encarnan el caos y la posibilidad de transformación social, la posibilidad de construir otro "orden" social. Encarnan la finitud y también la existencia humana, la capacidad de sobrevivencia. Encarnan el efecto no querido de lo que la norma dejó afuera. Si la norma produce o materializa aquello que nombra — joven natural—, también produce lo que escapa de ella, lo que quedó fuera — joven paródico-.

13. Butler, J. Cuerpos que importan. Buenos Aires: Paidós, 2002.

14. Op.cit. 


\section{Mabela Ruiz Barbot}

Por otra parte, estos jóvenes ponen en escena y repiten lo que los otros designan, volviéndolo otra cosa. Ellos y ellas son de la esquina, lo dicen a coro. Pero es una esquina que presenta otros contornos de los que la normalidad le otorga. Es la esquina signada por el discurso hegemónico y una esquina alternativa. La habitan y la multiplican. Allí se encuentran, allí están. No la abandonan porque las regulaciones la marquen y los marquen. Al contrario, la acatan y la pueblan. La calle es el lugar desertado de adultos, ellos la ocupan. La calle es el lugar de lo público, ellos lo habitan. Se apropian de los lugares públicos vacíos, que a la vez, llenan intermitentemente. El casamiento es un trámite legal y/o religioso, para ellos es una comedia. El consumo es el espacio actual de la vida social, ellos lo ponen en escena, lo dramatizan y ritualizan. Mueren de consumo. El aborto es lo indecible, inconfesable desde la mirada androcéntrica, ellas lo dicen, lo deciden, lo exponen, lo cantan. La adultez muestra el sentido trágico de la vida, el sufrimiento de sus otros adultos. Ellos no quieren vivirla de esa manera. Desde allí molestan, provocan. Desde allí dicen que es posible habitar otras relaciones sociales, otras relaciones intra-etarias e inter-etarias, otras relaciones de género. Desde allí dicen que es posible procesar las edades de otra forma. Desde allí rompen con todo anclaje y generan incesantemente nuevos contextos y suponen contextos posibles; intervienen en la construcción de sí mismos aunque no cuenten, las más de las veces, con las personas, relatos u objetos para acceder a su historia, a su nombre.

La vida los atraviesa, las condiciones existenciales y la experiencia los van configurando y ellos van habitando un lugar representacional de sí y un nosotros paródico, desafiante, resistente. Operan policitidad. Ellos, que como jóvenes son los que quedan fuera de la norma joven, los que viven el encierro (la cárcel) y no la libertad electiva, están diciendo que la categoría joven es una construcción política y que podría construirse de otra forma. Ellos/as, que como jóvenes viven también la adultez y son a quienes se les sustrae tempranamente la "jovialidad", están diciendo que las categorías joven y adulto son construcciones políticas y que podrían construirse de otra forma.

Despliegan la parodia y la acción política, la resistencia. Se oponen a una hegemonía simbólica e histórica. Sostienen, soportan y des-estabilizan el "orden" social, al joven natural, a una categorización del adulto y joven inventada, a una organización social inclusiva y excluyente.

\section{Narrativas de un lugar político-alterado}

Las experiencias vitales, narradas e interpretadas por unos otros y otras jóvenes, construyen variaciones de sentidos en el cruce de la edad joven con la clase social y el género; sentidos alterados. Alterados en tanto dan cuenta de los procesos de subjetivación y de la transformación de las subjetividades, de que lo juvenil no abarca integralmente al joven como persona, de que los y las jóvenes se viven siendo jóvenes y adultos al mismo tiempo, de que es posible la construcción de otra relación adulto-joven, la construcción de otra relación entre los sexos. Dan cuenta de la transformación de los sentidos. Se narran en un tiempo abierto.

Viven una experiencia anticipada y en el quiebre de esa experiencia. Se dejan atrapar por la incertidumbre, no saben de antemano a dónde los conducirá lo que viven y se dejan vivirlo. Dejan que la 
experiencia los atraviese, se abren a la experiencia, ella no está escrita, más allá de que esté condicionada socialmente. Se exponen y la viven. Construyen lugares híbridos de juventudes y adulteces. Apenas se nombran como jóvenes. Se abren a la experiencia de vivir otras feminidades y subrepticiamente, van interrogando la masculinidad tradicional. Realizan un trabajo sobre sí mismos. Intentan conservar la capacidad de asombrarse de sí mismos. Intentan mantenerse en su propia alteridad constitutiva. El otro los altera, los perturba, los interpela. Por lo pronto, ello se instala en sus espacios narrativos.

Son aquellos que viven su autonomía conociendo a otros, creando nuevos lazos, descubriendo mundo. Aquellos que son interpelados por los otros, fundamentalmente, por los jóvenes paródicos. Aquellos que se distancian de sus pertenencias sociales primeras, de sus pertenencias de la infancia y adolescencia. Aquellos que quieren conocer otra gente, otros jóvenes, otros adultos. Aquellos que quieren estar con otros/as, otros con quién de-construirse y re-construirse, que los movilicen, toquen, alteren. Aquellos que quieren mirar al otro, pensar con el otro y desde allí, pensarse a sí mismos. Se viven cambiando las formas de pensar, buscando trascender las categorías intra-etarias entre unos y otros jóvenes, los etiquetajes. Se vinculan con jóvenes diferentes y que atraviesan condiciones de vida desiguales. Conocen a otros jóvenes, gente en las plazas, en la calle, en otros barrios que no son los de ellos, en reuniones o encuentros que albergan siempre a algún desconocido. Callejean, observan la ciudad y a su gente, la interacción social. Son los terceros que operan, ilusoriamente, queriendo romper lo dicotómico, la construcción simbólica del joven natural y de aquel que este joven dejó afuera, el joven paródico. Aquellos que también eligen, pero eligen con quiénes encontrarse, vínculos de amistad, una posición política ante la polarización social, relaciones que no necesariamente son de su propio sector social de origen. Aquellos que se narran en la tensión entre sus condicionamientos sociales y la libertad.

Hay otras figuras jóvenes que dan cuenta de continuidades; pero no son las que queremos destacar aquí. Figuras jóvenes de sectores medios que perdidas de sí mismas aún no encuentran la oportunidad que ese otro/a joven les abre para pensarse en otra relación joven-joven, en otra relación adulto-joven, en otras relaciones sociales. Así repiten y refuerzan estigmas sociales. Narrativamente, dan cuenta de sí inestablemente, han vivido experiencias disruptivas, quiebres identitarios, han sentido su propia fragilidad y finitud, han sido en algún punto discriminados o violentados y, asimismo categorizan y estigmatizan a los otros ubicándolos en la anomia, los excesos o patologías, desde la incorporación del discurso adulto. Sabiendo, de forma latente, que en cualquier momento pueden ser ellos mismos quienes sean estigmatizados por los jóvenes naturales y los adultos.

En tanto que, los jóvenes que dan cuenta de continuidades y discontinuidades se construyen en un lugar de terceros que oscila, de forma paradójica, entre una posición caritativa o misericordiosa, que afirma que el joven paródico o diferente los interpela en su necesidad, en su reclamo, en que "le den derechos", en integrarlo al sistema y reducirlo a la mismidad, a lo homogéneo —el joven natural—, y una posición alterada en que ese joven paródico o diferente fisura, fractura, quiebra sus experiencias para re-construirlos en otra experiencia. Un otro que deja una huella en el sí mismo. Y ellos intentan re-construir lo colectivo, formas de solidaridad. Estarían también diciendo que es posible otra construcción política y social. 
La interacción de fuerzas múltiples les genera distintas posibilidades de vida. Toman fragmentos de la vida de los otros para sí, van habitando representaciones de sí que combinan fragmentos de vida de los padres, de los abuelos/as, de los hermanos/as, de los amigos/as, de los otros/as desiguales y diferentes. Se identifican con los personajes de los video-clips, de la música. Toman de cada lugar que habitan o van habitado, lo que el lugar les da, van construyendo significaciones múltiples. Unos trabajan, otros no, se forman con otros/as, se proyectan cambiando de trabajo o en no saber en qué van a estar dentro de unos años, quizás haciendo otra cosa a la que hacen hoy. Viajan, experimentan otras culturas o las observan distanciados, las confrontan a la propia, las cuentan e interpretan.

La experiencia familiar los ha situado en vidas no lineales, en movimiento, cambiantes; llevándolos a atravesar condiciones de vida disímiles en distintos momentos o en un mismo momento de su vida. Condiciones inestables y estables de vida, al mismo tiempo; viven la inestabilidad de un hogar parental y la estabilidad en el otro hogar parental. Transitan por más de una casa, viven con los padres, viven días en la casa del padre y con otros y otros días en la casa de la madre con otros, viven con los/ as novios/as en la casa parental, viven en una casa parental unos días y otros días en la de la pareja, viven con amigos de ambos sexos, viven con otros cambiantes. Sus vínculos familiares y de amigos cambian y con ello, los sectores sociales en que se relacionan.

La experiencia de género les ha abierto, a estas mujeres jóvenes, posibilidades para pensarse, significarse y dar cuenta de sí mismas en feminidades que intentan romper con los mitos de la feminidad tradicional. Dan cuenta de la aprehensión subjetiva de relaciones sociales e históricas sexistas y de la posibilidad subjetiva de transformar el sentido de sus experiencias femeninas. Se cuentan socializadas y viviendo relaciones androcéntricas, al mismo tiempo que rompiendo con ese tipo de relaciones. Así narran sus transformaciones y amplían feminidades. Rompen con historias familiares de mujeres o por lo pronto, las interpelan. No quieren repetir esas historias. Y recuperan aquellas voces familiares que las invitan y animan al despliegue de sí como mujeres. Trascienden la domesticidad, habitan espacios públicos. Envuelven para sí el desarrollo intelectual. Viven su sexualidad, la vida en pareja sin nupcialidades de por medio. Se posicionan construyendo sus maneras de vivir. Sus narrativas ponen en juego feminidades en relación a su posición de clase, su posición política, su etnia, sus edades como mujeres jóvenes. Algunas mujeres jóvenes de los márgenes buscan distanciarse de la experiencia de otras mujeres jóvenes y pobres marcadas por la maternidad, por la dependencia de un varón proveedor y dan lugar a la construcción posible de otras representaciones sociales de sí y para sí. Encarnan el sufrimiento de clase y de género, el desprecio y humillaciones de los otros; y conflictivamente, construyen su feminidad desde esos dos lugares, situadas en el cruce de desventajas y la potencia de sí. Al igual que mujeres jóvenes de sectores medios, intentan cuidarse a sí mismas, el gobierno de sí y la paridad en las relaciones entre los sexos. Alguna que otra figura masculina, se relata interrogando su masculinidad, oponiéndose a la individualización de la vida, dando cuenta de sí desde lo emocional, lo espiritual, en el cuidado de otros o apostando a ello. Se sienten interpelados por los otros, varones y mujeres.

Ellos y ellas construyen sentidos desde los cambios que han experimentado, sentidos provisionales. Y estos sentidos se ligan a sus condiciones de existencia, condiciones también cambiantes. Se narran en condiciones de vida que los han limitado y limitan y que les han abierto posibilidades. Distintas 
posiciones sociales han atravesado o están atravesando sus vidas. Han vivido ascenso o descensos sociales abruptos-no abruptos, han interactuado o interactúan con jóvenes de distintos sectores sociales. Se cuentan signados por los procesos sociales, por una dictadura que no la vivieron pero los ha tocado, el fracaso de la Ley de caducidad de la pretensión punitiva del Estado, el cierre de fábricas y la desocupación de los padres, la crisis del 2002, por la violencia de la corrupción y la pasividad social, por la militancia de los padres, por guerras y destierros en las historias ancestrales. Construyen sentidos ficcionales, se viven por momentos fuera del mundo, mirándolo desde la distancia. Cuentan que, como Mafalda, quieren parar el mundo, se quieren bajar. Se sienten interpelados por los que viven en la calle y a la vez, por un Sur con el cual se identifican.

Un sentido de compromiso social, ciudadano y político, los envuelve y lo narran. Hablan desde un nosotros comunitario que no necesariamente es un nosotros joven. Un nosotros politizado que distingue y liga lo joven y no joven.

Se van posicionando política e ideológicamente, oponiendo a determinadas significaciones, prácticas, valores - a maneras de vivir burguesas, al privilegio de la productividad y de la eficiencia en el trabajo, a una vida superficial o light, a la injusticia social- . No entienden algunas cosas, no tienen palabras para explicar otras, se posicionan desde allí. Van encontrando otros lenguajes, no los van encontrando. Conflictivamente, se viven en la posibilidad de transformar su vida cotidiana. Se presentan en su multiplicidad como sujetos, en lo fugaz, finito y cambiante. Se presentan desmarcándose de estereotipos juveniles, ensayando otra posición social desde una posición social de origen obrero. Buscan romper condicionamientos existenciales a través del deporte. Rechazan simbólicamente su condición social —media alta-, desde su condición etaria. Experimentan fuerzas étnicas y comunitarias que los animan a romper con sus herencias socio-culturales. Cumplen mandatos parentales y tratan de alejarse de sus condiciones existenciales. Viven entre viejas y nuevas pertenencias sociales, debatiéndose en sus posiciones de clase ante la movilidad social vivida. Construyen sentidos que les permiten inscribirse socialmente ante la experiencia de des-clasamiento en que viven. Se permiten resistir su experiencia de clase media, a la vez que le dan forma.

Fundan representaciones de sí, habitan sentidos desde relatos familiares e historias sociales, re-significados al hoy. Perturban la quietud o pasividad adulta desde la música que escuchan. Tensionan sus posiciones sociales, experimentan su posición etaria y legitiman sus feminidades a través de la música. Se empoderan como mujeres desde distintas posiciones sociales y confluyen en el intento de transformar las relaciones entre los sexos. Confrontan sentidos, significaciones, maneras de vivir de los jóvenes naturales. Trabajan para la ciudadanía antes que para el mundo burgués. Gobiernan en la "edad joven".

Cuestionan la individualización de la vida y paradójicamente, la viven; se realizan personalmente y recuperan sentidos en sus orígenes obreros o étnicos. Se desligan de la creencia en la capacidad ilimitada de las personas de realizarse de forma independiente a todo condicionamiento y contingencia histórica-social, sin narrarse en el condicionamiento absoluto. Reconocen a otros que viven en condiciones desiguales, se dejan interpelar por ellos y ellas. 
Son algunas figuras jóvenes que se posicionan en lugares alterados. Figuras que nos están diciendo que los viejos ritos de transición a la adultez no los construyen, ni tampoco solamente la categoría joven. Nos están diciendo que son las condiciones existenciales en sus múltiples dimensiones quienes fundan maneras de vivir jóvenes y que ellos/as, como sujetos sociales, trabajan sobre sí mismos y el colectivo intentando producir otro procesamiento de las edades.

De este modo, se presentan siendo niños, jóvenes y adultos al mismo tiempo. Se relatan posicionados en un lugar híbrido, un lugar que no es joven ni es adulto. Han transitado por lugares adultos siendo adolescentes y jóvenes, tienen la capacidad de retornar a la niñez, de pensar y re-escribirse desde allí. Viven entre la adultez y lo juvenil, entre las edades, procesando etapas de la vida construidas política y socialmente. Juegan siendo niños y jóvenes, revelando que el adulto también juega o puede jugar. En su cotidianeidad, entrelazan prácticas jóvenes y prácticas adultas. Toman decisiones, asumen compromisos económicos familiares, construyen estrategias de vida, viven pérdidas y frustraciones, participan política y socialmente.

Buscan descubrir otros espacios adultos y no tienen palabras que los nombren. Se nombran desde discursos adultos y luego, deslegitiman esa forma de nombrarse. Interpelan a los adultos y se interpelan a sí mismos desde la mirada adulta. No cuentan con palabras que nombren la adultez fuera del aburrimiento, la rutina, una "vida ya hecha", la formalidad, el conformismo, una vida lineal y en la mismidad, homogeneidad. Presentan al adulto siendo uno. No cuentan con un lenguaje para pensar al adulto y proyectarse adultos en la persistencia de la transformación de sí, a través de los acontecimientos que vayan viviendo. Representan a los adultos como personas "independientes"; es decir, que no necesitan a nadie, que reprimen su necesidad de los otros y del intercambio de experiencias. Y se representan a sí mismos rompiendo rutinas, viviendo el desorden, provocando nuevas experiencias, equivocándose, gozando, trasgrediendo los mandatos del mundo adulto. Estarían disfrutando lo que luego, como adultos, les será clausurado. Se oponen a ese mundo adulto, se distinguen de ellos a través de marcas jóvenes, para luego desmarcarse tanto de ese lugar joven construido como de ese mundo adulto poderosamente ficcional.

Sienten una fisura o hueco entre el mundo adulto y sus mundos, una brecha inter-generacional. Sienten que el mundo del adulto es un lugar marcado por el olvido, por la imposibilidad de retornar a la niñez, adolescencia y juventud, a esos lugares que, aunque inventados, están allí para, cada tanto, recoger aquellas marcas que permiten tejer o entramar nuevos sentidos de y en la adultez (Forster, 2009 $\left.{ }^{15}\right)$. O como dijera Foucault (2008) ${ }^{16}$, parecería que buscan palabras que les permitan narrar que "el objetivo no es prepararse para la vida adulta (...) sino el prepararse para cierta realización completa de la vida", que está lejos, muy lejos de la realización de sí o individualización de la vida. La realización es completa en el momento anterior a la muerte. Narrar que se preparan, simplemente, a vivir y que están viviendo, que su presente es vida.

15. Forster, R. Los tejidos de la experiencia. En Experiencia y Alteridad en educación. Santa Fe-Argentina: HomoSapiens Ediciones, 2009.

16. Foucault, M. Tecnologías del yo. Y otros textos afines. Barcelona: Paidós, 2008. 
Dan cuenta de su momento socio-histórico como jóvenes y buscan que su voz se escuche. Problematizan su lugar social como jóvenes, intentan des-naturalizar la relación adulto-joven, ponen en juego las ambigüedades, tensiones e incomodidades que viven desde dicha relación de poder. Reclaman una mirada de reconocimiento de su integralidad como sujetos. Fundan lugares de autonomía, van ampliando sus lazos sociales. Se desmarcan de un tránsito lineal a la adultez.

Narran que viven en un lugar híbrido y que es posible otro procesamiento de las edades, otra construcción de lo juvenil, otra construcción de la adultez.

En síntesis, estos tres lugares sociales revelan las condiciones de polarización social como una construcción simbólica, política e histórica. A su vez, develan relaciones entre los sujetos jóvenes. Sus voces estarían interpelando las propias condiciones de polarización o individuación y las relaciones desiguales adulto-joven que los producen como sujetos jóvenes.

Los sentidos electivos de vida que componen un lugar político-naturalizado de los y las jóvenes, dan cuenta de la norma social, de la construcción de hegemonía, de la dilución ilusoria del mundo adulto, de una nueva categoría joven o desigualdades sociales-categoriales intra-etarias. Revelan a unas figuras jóvenes que encarnan una voluntad de verdad y poder que es contestada, interpelada, parodiada por otras figuras jóvenes que construyen sentidos de resistencia y sobrevivencia ante los procesos de exclusión de los cuales son objeto. Ambas son figuras políticas, antagónicas, relacionales. Figuras construidas, espacios simbólicos. Los sentidos electivos muestran a unas figuras que viven en la naturalización de la existencia social. Los sentidos resistentes muestran a otras figuras que les contestan, que entran en relación con ellas y les dicen que sus figuras son ficcionales, construidas histórica, política y socialmente. Y que se puede construir otra forma de organización social, otra forma de relaciones entre las edades. Entre ellas operan las figuras de terceros dando cuenta de sentidos alterados, de la transformación de sentidos, ya que han vivido y viven experiencias sociales, familiares, de género cambiantes. Habitan representaciones provisionales de sí, al igual que aquellas figuras que construyen lugares políticos-paródicos. Junto a estas figuras han vivido experiencias de fisura o quiebre de sus identidades. Sería, entonces, en el espacio simbólico donde los sujetos jóvenes entran en relación. Espacio donde se parodia y politiza la vida como construcción social y se interpela lo juvenil como construcción política, en este momento histórico.

\section{Conjugando las narrativas biográficas}

El foco en las narrativas, deudor del giro biográfico en las ciencias sociales e inscripto en la tradición constructivista, nos permitió revisar cómo los agentes sociales construyen y ponen en sentido sus experiencias vitales.

La narrativa biográfica de los lugares sociales-jóvenes puso en juego experiencias juveniles de politicidad o la politicidad de las experiencias juveniles, formas de resistencia al mundo adulto, al mundo institucional y social. Los y las jóvenes se instalan en la duda ante lo familiar y obvio, ante los mandatos y anticipaciones adultas, ante lo hegemónico y naturalizado, la norma social y las regulaciones de 
la población joven, ante la estereotipa de género, prescripciones y atribuciones sexistas. Politicidad, quizás, sólo reconocible a través de los relatos ante la multiplicidad de experiencias jóvenes y la estigmatización de los jóvenes paródicos.

Dicho foco, hizo perceptible o reconocible que en los y las jóvenes habitan, conflictivamente, sentidos anticipados-adultos junto a aquellos que van desnaturalizando, deslegitimando y construyendo al momento de narrar, mirar y significar su experiencia. Sentidos que no suturan sentidos. Abiertos... Toman y usan sentidos adultos para inscribirse socialmente, ya que son compartidos. A la vez, esos sentidos se oponen a su experiencia, a lo que les está pasando. Narran, entonces, entre sentidos, a dos lenguas. Intentan desanudar sentidos ajenos y dudosamente, tejen otros. No encuentran y encuentran palabras, otra lengua que los signifique.

Visibilizó experiencias de trabajo sobre sí mismos, procesos de transformación de las subjetividades producto del momento socio-histórico y las condiciones existenciales de cada quien. Una época en que las jóvenes, fundamentalmente, transitan por procesos reflexivos en la construcción de nuevas feminidades y en su relación con el otro sexo. Las jóvenes narran, de cierta forma y de manera conflictiva, la experiencia de su propia transformación, otros sentidos posibles de su experiencia femenina. Una época en que se silencia la construcción de las masculinidades o en que los varones se interrogan sigilosamente sobre la masculinidad tradicional, al mismo tiempo que fugan hacia ella en su espacio narrativo, ante otros sujetos.

Dio cuenta de los antagonismos constitutivos de experiencias situadas de clase, una zona de articulación variable de experiencias, significaciones y atributos que interpelan a unos y otros jóvenes de distintas posiciones.

Hizo visible el conflicto social a través de la confrontación de las condiciones existenciales de unos y otros jóvenes - expresadas en múltiples dimensiones, del territorio en que viven a las maneras de vestir, a modo de ejemplo-, de las experiencias vitales y sentidos emergentes de dichas condiciones, así como en la emergencia de desigualdades-categoriales jóvenes que designan quiénes son los unos y los otros, hoy. Al mismo tiempo, dio cuenta de alteraciones de posiciones de clase en su cruce con posiciones étnicas, de género y etarias, diagramando rupturas simbólicas, rupturas posibles con una herencia cultural. La movilidad social —ascensos y descensos sociales-, por su parte, interceptó las maneras de vivir y representarse de los y las jóvenes, situándolos en una experiencia de la cual emergen sentidos dispares, contrarios, inciertos y abiertos que movilizan al propio sujeto hacia otras representaciones de sí y quizás, construcciones colectivas posibles, aunque desconocidas.

Dejó entrever la articulación entre las condiciones existenciales y los procesos de subjetivación de los y las jóvenes y cómo, en dicha articulación, se producen sentidos, lugares sociales. Observar ante los cambios sociales, estructurales, el movimiento o metamorfosis de las subjetividades y de la primacía hegemónica de la acción de unas instituciones sociales frente a otras cuando las condiciones de vida se han polarizado. Si en épocas de integración social, la fábrica era el lugar de explotación de los trabajadores y los obreros se significaban como clase demandando otra distribución de la riqueza y por tanto, justicia social, llevando adelante la transformación social; si la universidad asumía un papel sustancial acompañando dicha transformación y los jóvenes se significaban militando, actuando colec- 
tivamente en movimientos estudiantiles; hoy, la cárcel ocupa, hegemónicamente, el lugar del poder por excelencia, en tanto la interacción social se significa desde la inseguridad y al joven paródico se lo vive como amenaza, criminalizándolo y estigmatizándolo. Estos jóvenes como "clase peligrosa"17, hoy, estarían tensionando el "orden social". Intermitente y desorganizadamente, reclaman justicia y transformación social dejando ver que es posible construir otra forma de organizarnos colectivamente.

Esta perspectiva reunida en la narrativa biográfica posibilitó aproximarnos a la existencia del sujeto, a las experiencias que dan sentido o no a una vida, al recorrido o camino que va y está haciendo, donde camino y caminante van juntos. Ir más allá de la manera en que los estudios socio-demográficos sobre juventudes en Uruguay han tratado el tema de las trayectorias vitales de los y las jóvenes, la relación entre la norma social e institucional y la posición que ocupa el sujeto, con respecto a la misma, en su recorrido singular. Las posiciones que va adquiriendo en la transición a la vida adulta (en la familia, educación, trabajo, etc.).

Habilitó construir y situar el análisis en una perspectiva de la experiencia narrativa, entendiendo que todo sujeto en toda edad se encuentra condicionado y viviendo acontecimientos disímiles. Se encuentra buscando sentidos personales, relacionales y colectivos, atravesando experiencias y recuperando otras vividas en otras edades, reflexionando el presente desde lo que le pasó y hacia lo que está por-venir, abriendo posibilidades de ir más allá de lo dado y hacia otro lado, hacia un territorio abierto y plural, un tiempo que esté lleno de dislocaciones, de rupturas, de mutaciones sorprendentes, de giros inesperados. Cada objeto y/o relación puede estar guardando la posibilidad de un mundo en estado de promesa, si es que tanto los y las "jóvenes" como los "adultos", dejamos que nos pase algo (Forster, 200918; Sennet, $2003^{19}$; Skliar y Larrosa, 2009 ${ }^{20}$ ). Se puede vivir la adultez retornando a "lugares jóvenes", habitar la "edad joven" experimentando "lugares adultos", intercambiablemente, si las temporalidades fuesen vividas en su multiplicidad y lejanas a una linealidad, si la historia de cada quien fuese vivida como sorpresa, inquietud, estado de catástrofe y/o de excepción, de efervescencia y pasión (Forster, 200921; Skliar y Larrosa, 2009 22). Procesar edades puede significar, entonces, vivir cada momento etario en un ir y venir entre lo que le está aconteciendo al sujeto hoy, las huellas del pasado que retornan en ese momento desde la experiencia vivida en otra edad y el lugar representacional de sí que está construyendo y habitando siempre de forma política, relacional, narrativa y como anticipación de un posible por-venir; para luego pasar a vivir otro momento.

17. Castel, R. La inseguridad social. ¿Qué es estar protegido? Buenos Aires: Manantial, 2004.

18. Op.cit.

19. Sennett, R. El respeto. Sobre la dignidad del hombre en un mundo de desigualdad. Barcelona: Editorial Anagrama, 2003.

20. Skliar, C. y Larrosa, J. Experiencia y alteridad en educación. Santa Fe-Argentina: HomoSapiens Ediciones, 2009.

21. Op.cit.

22. Op.cit. 


\section{Mabela Ruiz Barbot}

\section{Bibliografía}

Arfuch, L. El espacio biográfico. Dilemas de la subjetividad contemporánea. Buenos Aires: Fondo de Cultura Económica, 2007.

Brockmeier, J. y Harré, R. “Narrativa, problemas y promesas de un Paradigma Alternativo”. Psicología, Reflexión y Crítica, Brasil, 2003.

Butler, J. Dar cuenta de sí mismo. Violencia, ética y responsabilidad. Buenos Aires: Amorrortu, 2009.

Castel, R. El ascenso de las incertidumbres. Trabajo, protecciones, estatuto de individuo. Buenos Aires: Fondo de Cultura Económica, 2010.

Chamberlayne, P.; Rustin, M.; y Wengraf, T. Biography and Social Exclusión in Europe. Experiences and life journeys. Bristol: The Policy Press, 2002.

Chaves, M. "Juventud negada y negativizada: Representaciones y formaciones discursivas vigentes en la Argentina contemporánea". Última Década № 23, pp. 9-32 Valparaíso: CIDPA, 2005.

"Investigaciones sobre juventudes en la Argentina: estado del arte en ciencias sociales 1983-2006", Revista Electrónica del Instituto de Altos Estudios Sociales de la Universidad Nacional de General San Martín, № 5, Año 2, Buenos Aires:, 2009.

De Gaulejac, V. La neurosis de clase. Trayectoria socialy conflictos de identidad. Paris: Hommes \& Groupes, 1987.

El costo de la excelencia. Conferencia 28.10.2008. Buenos Aires: Mimesis, 2008.

Denzin, N. K. Interpretative Biograhpy. Newbury Park, CA: Sage, 1989.

Elizalde, S. ¿¿Qué vas a hacer con lo que nos preguntes? Desafíos teóricos y políticos del trabajo etnográfico con jóvenes institucionalizados/a", KAIROS, Revista de Temas Sociales. Año 8 - № 14, Argentina:. Universidad Nacional de San Lui, 2004.

Enriquez, E. El sujeto humano: de la clausura identitaria a la apertura al mundo. En el inconsciente y la ciencia. Buenos Aires: Amorrortu Editores, 1993.

Espíndola, F. "De jóvenes "ni, ni" que habitan Casavalle. Representaciones sociales desde espacios de exclusión". En Juventud como objeto, jóvenes como sujetos, Revista de Ciencias Sociales, Año XXII, N 25Montevideo: Departamento de Sociología, Facultad de Ciencias Sociales, 2009.

Filardo, V.; Cabrera, M. y Aguiar, S. Encuesta Nacional de Adolescencia y Juventud 2008, Segundo Informe. Montevideo: Edición Infamilia-MIDES, 2010.

Foucault, M. Las palabras y las cosas (28a. Edición). Madrid: Siglo Veintiuno Editores, 1999. 


\section{En el contexto uruguayo, narrativas biográficas y lugares sociales}

de los y las jóvenes

Fraser, N. "La justicia social en la era de las "políticas de identidad": redistribución, reconocimiento y participación". Apuntes de investigación del CECYP. № 2/3. Año II, 1998.

Gatti, G. "Algunas anécdotas y un par de ideas para escapar de las ficciones modernas acerca de la identidad colectiva". Berceo, № 153. pp. 13-26; Logroño-España, 2007.

Infamilia-MIDES Uruguay: jóvenes y adolescentes dicen. Encuesta Nacional de Adolescencia y Juventud 2008. Informe Preliminar. Montevideo; Edición Infamilia, 2009.

Lacapra, D. Historia en tránsito. Experiencia, identidad, teoría crítica. Buenos Aires: Fondo De Cultura Económica, 2006.

Lamas, M. "Diferencias de sexo, género y diferencia sexual". Redalyc. enero-abril, año/vol. 7.número 018. Escuela Nacional de Antropología e Historia. México, Cuicuilco, 2000.

Llobet, V. ¿Fábricas de niños? Las instituciones en la era de los derechos de infancia. Buenos Aires: Noveduc Libros, 2010.

"Un mapeo preliminar de investigaciones sobre infancia y adolescencia en las ciencias sociales en Argentina desde mediados de la década de 1990". KAIROS. Revista de Temas sociales. Proyecto Culturas Juveniles. Año № 15. № 28. Noviembre. Argentina: Universidad de San Luis, 2011.

Merklen, D. Pobres ciudadanos. Las clases populares en la era democrática (Argentina, 1983-2003). Buenos Aires: Editorial Gorla, 2005

Oyarzun, P. Walter Benjamín. El Narrador. Introducción, traducción, notas e índices de Pablo Oyarzun R. Santiago de Chile: Ediciones Metales Pesados, 2010.

Pampillo, G. y otros. Una araña en el zapato. La narración. Teoría, lecturas, investigación y propuestas de escritura. Buenos Aires: Libros de la Araucaria, 2004.

Reguillo Cruz, R. Emergencia de culturas juveniles. Estrategias del desencanto. Buenos Aires: Norma, 2000.

Rodríguez, E. "Juventud, desarrollo social y políticas públicas en América Latina y El Caribe. Oportunidades y desafíos". Cap. IV. Costa Rica: FLACSO, 2002.

"Jóvenes y cohesión social en Uruguay: ¿de la invisibilidad al protagonismo?" CLAEHSecretaría General Iberoamericana-OPP-AECID, Montevideo, 2011.

Saraví, G. "Biografías de Exclusión: desventajas y juventud en Argentina”. En Perfiles Latinoamericanos, julio-diciembre, número 028. Distrito Federal: México: Facultad Latinoamericana de Ciencias Sociales, 2006.

Scott, J. El género: una categoría útil para el análisis histórico. En: Lamas, M. (Comp.). El género: la construcción cultural de la diferencia sexual. México: PUEG. 265-302, 1996. 


\section{Mabela Ruiz Barbot}

“Experiencia". Revista Hiparquía, Vol.10, № 1, pp. 59-83, Buenos Aires: Asociación de Mujeres en Filosofía, julio 1999.

Skliar, C. "La crisis de conversación de alteridad". Facultad Latinoamericana de Ciencias Sociales. FLACSO-Argentina. Consejo Nacional de Investigaciones Científicas y Tecnológicas de la Argentina, s/d.

Smith, B. y Sparkes, A. "Contrasting perspectives on narrating selves and identities: an invitation to dialogue". Sage: Qualitative Research. February, vol. 8 № 1 pp. 5-35, 2008.

Viñar, M. Mundos adolescentes y vértigos civilizatorios. Montevideo: Editorial Trilce, 2009.

Viscardi, N. “Delitos, trayectorias de vida y procesos socializadores de jóvenes vinculados a Programas de Rehabilitación. Puertas cerradas, vida hacia adentro". En Educación y Juventud. Problemas Actuales y Abordajes Teóricos. Revista de Ciencias Sociales, Departamento de Sociología, Facultad de Ciencias Sociales, Año XIX, № 23: Montevideo, 2006.

Wacquant, L. Los condenados de la ciudad. Gueto, periferias y estado. Argentina: Siglo XXI Editores. 2da edición, 2013. 